\title{
Clown Images in American Movies in Recent Years Under Postmodernism
}

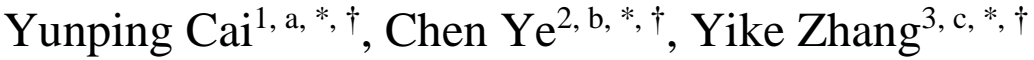 \\ ${ }^{1}$ Communication University of China, Nanguang college \\ ${ }^{2}$ NanJing Normal University \\ ${ }^{3}$ University of Derby \\ *Corresponding author email: ${ }^{a}$ sannycellardoor@163.com, ${ }^{b} 21190305 @ n j n u . e d u . c n$, \\ c100551965@unimail.derby.ac.uk.
}

${ }^{\dagger}$ These authors contributed equally.

\begin{abstract}
This essay uses the postmodernist theory to explain the clown image in American movies. The author sorts out the definition of the role of the clown and summarizes the changes of a clown under postmodernism. In addition, from recent year's American films, such as IT, The Dark Knight, and Joker (2019), the author adopts specific image analysis and traces the reasons behind it. The essay will see the concept of Postmodernism in the change of the role of the clown. In postmodernism, the original order is broken. The absurd world may be more in line with the reality of the subverted world.
\end{abstract}

Keywords: Clown, Postmodernism, Image analysis, Historical outline.

\section{INTRODUCTION}

As America come to a post-industrialized and highly commercialized era, jokers, who shared a historical origin with entertainment and recreation industries, again flourishing nowadays in one of the most influential media types: films. From historical background to screen analysis to current social theories, this essay means to probe into these questions: how did the image of joker reform throughout history? What kind of reformation does it achieve on the screen? And what are the sociology and physiology reasons behind jokers' emergence and its evolvement? The analysis hopes to unlock the key to these changes and help some media workers to understand the utility and prospects of this specific type of character. The essay will answer these questions based on post-modernist methodology.

\section{HISTORY OF THE CLOWN}

Clowns are one of the most common comic characters today. They often entertain the audience with their eccentric and funny costumes and funny body movements. Still, at the same time, their performances also show great wisdom and insight into social life that cannot be ignored. Jan Kott wrote: "Role is generated from the actor's performance of characters in the drama, and its implied meaning is formulated or constructed for a specific purpose. It gives people the impression that it is functional and has no personal will [1]." Clowns, marked by colorful clothes, show a hybrid personality that is easily changeable on the stage, and their goal is to realize the (professional) entertainment function of the dramatic role. The clowns mentioned in this article are clowns in western society and the art field. They frequently appear in daily life and different literary works. The images of these clowns and the cultural meanings behind them are constantly changing.

\subsection{The origin of the clown}

The clown image has a long history in Western culture, and at first, it was not given that much cultural connotation. The profession of "clown" originated around the 14th century A.D. and was originally a kind of comic performer for the lords and nobles of the court. With the secularization of the 16th century, comedy shows went to the masses, so clowns were no longer confined to the palace space but more widely walked into the countryside and towns. Around the 18th century, the image of a clown was associated with a sinister connotation of comical, indecent, or insanity. Since then, 
the word "clown" has been derogatory in many uses and is no longer a friendly term. But in any case, the clown figure had become a widespread part of everyday life by that time.

\subsection{From historical facts to cultural expressions}

With the development of western society, the image of "clown" has been endowed with more and more complex elements. The complex features of his images are particularly evident in the field of literature and art. Literary clowns have evolved from a historical fact to a cultural expression. In Shakespeare, the clown is a very popular figure. Although Shakespeare retained the stereotypical character definition of the clown as a mere joke maker in the plot, Shakespeare created another clown character as a wise man. Although Shakespeare's clowns are always on the surface of a gag, acting silly, some truth is often spoken through their mouths. The character of Touchstone in As You Like It is a fool who always says something of wisdom. Shakespeare's King Lear is best known for its clown character. The character is cast as a sort of prophet of tragedy. The gloom and pain behind the smile. The image of a clown who knows the truth but can only express it in an obscure and tortuous way, a dialectical and contradictory character, was established as early as Shakespeare's time. In Edgar Allan Poe's Hop-Frog, the clown is once again associated with revenge and murder. The clown in Hop-Frog seeks to avenge the emperor's mistreatment of a maid. But in the face of power, they must play clever means to achieve their goals. This shows that the clown's "justice" is very dialectical, and his goodwill is contained in the evil. Because the Joker is so weak, he must use lies and tricks to get his revenge. By this time, the clown already has the image of subtle and tortuous resistance to the power hidden. Similarly, the Joker character in Hugo's The Laughing Man, the antipode of court intrigue and a symbol of justice, was later borrowed into the Batman series and unexpectedly became the main villain. Thus, the distinction between good and evil in the development of the clown image is very blurred. The image of the clown hides suffering and tragedy behind a smile, threatening the justice claimed by the powerful with a gesture of mockery and satire.

\subsection{The change of clowns under the influence of postmodernism}

The image characteristics of clowns are more and more contradictory and pluralistic in the process of development and change. At first, we can conclude that the common characteristics of clowns are "comedians, persons with physical disabilities, persons adept at pleasing aristocrats for their advantage". However, under the influence of the post-modernist philosophical trend of thought in western society since the 1960 s, clowns, as a spiritual symbol representing the rebellious spirit and free ideological trend after people's literary processing, have expressed strong anxiety and satire the post-modern industrial social life. Clowns have moral defects to a certain extent in literary works, and at the same time, they also carry the rebellious spirit of resisting order and power. They are representatives of honest and temperamental people. Orsay Dean said, "In the end, the meaning of commenting on postmodernist works, postmodernist novels or stories is largely left to the audience and readers [2]." Under the influence of postmodernism, people replaced the image of the clown with an ambiguous image; Replace explicit unity with the clutter of this and that. In post-modernist social life, new media methods, represented by films, have been developed. The common characteristics of clowns have been retained, and those that are more contradictory and diversified after artistic processing have also been strengthened with the application of new media methods. These contradictory and pluralistic characteristics are especially reflected in the clowns in American movies in recent years under the influence of post-modernism.

\section{ANALYSIS OF CLOWNS' ROLES}

If we take a close look at the film history, we could find the role of jester even from the earliest days. As Foucault noted in Madness and Civilization: " ... they were both threat and mockery, both the irrational giddiness of the world, and the pitiful laughingstock of mankind". L'arroseur arrosé, one of the first films made in French, applied the strategy of bringing in amusing characters to capture audiences' attention. Let alone the prestigious film artist Charlie Chaplin with his Tramp design, being a successful laughter maker and a harsh whip for the dark side of humanity at the same time. Recently, American films and their audiences have witnessed the monumental transformation of Jokers' screen images, as movies are using jokers to be their protagonists or anti-heroes. Take IT, The Dark Knight, and Joker (2019) for examples. With their unique aesthetic designs and commercial success, these films fill up lost pieces of the puzzle of how audiences, who are trained by consumerism, view the identities of such an original type of character, who firstly appear in comedy, now in this postmodern world.

\subsection{Character design: from flat to round}

The joker's figures undergo the evolutionary process from flat to round, as the external characteristic gradually transferring into internal traits. Red balloons and squeaking laughter were bounded with murder and blood in the horror film IT, a film that rewrites the familyfriendly, joy-bringing clown to the source of childhood trauma. As the clown lurks in the dark corner of the streets, audiences' speculation was easily bound with menace and evilness. Thus the image of the clown was 
unsurprisingly associate with fear. But that's a shallow impression based on visual horror. Later, Batman: The Dark Knight, a comic-adopted commercial movie, rises Clownstrophobia to a new level by depicting the psychotic Gotham joker and his astonishing crimes. A joker playing by Heath Ledger amazingly becomes the number one villain in film history and brand a moral panic inside his audiences' hearts. Thanks to the pandemic that media jokers brought us, children are not the only ones who fear jokers. Adults also found themselves caught in distress with the existence of strangers who dressed in colorful paint. As the time came to 2019, while the consumerism dressed up their favorite roles and the highly industrialized world turned individual into nameless nobody who runs along with them, another film merged. Joker forced us to view the world from a mentally suffered clown's eyes, a brandnew perspective different from the previous flatten jester role. He, who played by Joaquin Phoenix, is not an alone villain (contrast to the lone hero) anymore, but a parody of common folks. Jameson noted, "in the age of corporate capitalism, of the so-called organized man, of bureaucracies in business as well as in-state, of demographic explosion-today, that older bourgeois individual subject no longer exists [3]”. By removing personal heroism from the joker's characteristic, individualism was dead, which bring him down to the size of an average man. The character design thus bestows a universal meaning: the joker is real; the joker can be anyone.

\subsection{Storytelling: from antagonist to protagonist}

From Batman: The Dark Knight to Joker, the previous antagonist became the protagonist since the film is more of a piece of art than a commercial adoption. Batman: The Dark Knight shows the conflict between law and order with the chaos and violence and propagates it as their hottest selling product. In contrast, the Joker reviewed these concepts and raised a completely different opinion: why trust in justice since the law failed to protect those in desperate need of help. As cultural features turn from hierarchy to anarchy [4], the problems that modernism or previous genre haven't include became major topics of postmodernism cultural product. Indeed, as the film going, audiences came face to face with the most urgent problems and dimmest situations that a postmodern world could possibly offer: domestic violence, bullies, unemployed, mental disease, shrinks of fundamental facilities. The problems seem too ubiquitous, even banal. A dangerous latent idea alongside with equivalence amount of compassion was conveyed to us: what could you do when the bad things happened, and no help was delivered? The answer is thin and cynical: no way except to treat an injustice with injustice. And that is how Joker subverts the same topic in Batman: The Dark Knight and creates another layer of terror, from total trust in disciplines, it turns us to dubious queries. Thus the transformation from a notorious antagonist to a touching hero is made, and the character joker is reverted to its starting point. He is no longer a paper-thin character who works as a silver lining for dashing heroes, but a living human being who struggles through his inner demon. As Jean-Francois Lyptard decribed postmodernist protagonist: "losing its great hero, its great dangers, its great voyages, its great goal."[5]

\subsection{Editing function: from montage to full- length shots}

Besides the screenplay, the flowing deformation along the variation of the joker figures can also be found in the photography and editing technique as the traditional Hollywood styles battle with an authentic narrative way. While quick cutting of multi-camera clips adds suspension and imagination space, the slow pace in narrating makes a story run deep. In The Dark Knight, scenes were carefully selected to show cut-throat combat scenes. The spectacle was made, the special effect was pedestrian. Unreal shots combined with upbeat music and striking images help The Dark Knight pose itself as a successful commercial. In Joker, a similar technique was rarely seen. Instead, the honesty and cruelty of the cameras rather occupy the story. The long clips take the place of montage. Domestic situations such as apartments, stores, and bathrooms confined the character within them, thus creating a suffocating sensation. By framing the character inside the pictures, there is nowhere to run, both for the audience and the audience. In one of the most intense scenes in the film Joker, as the protagonist took shelter in a bathroom after the murder of three strangers, a full-length shot silently records the following transition procedure. This shot has become the key turn of the story since later on from that shot. We can see the joker is looking at himself through the mirror as if he were able to poke through the silver screen and stare at the audience, us. Variety narration modes deepen the theme of Joker, the language and texture used in it like its kin in Europe [6]. Full-length shots replace the Gestalt psychology pattern [7] while audiences are watching.

In recent American films, the joker figures bestow a more profound content than their earlier role, which serves as a simple contrast to the heroes. From flat to round, from antagonist to protagonist, from unitary narration mode to diverse styles, the jokers gain their weight in all sorts of media types. The transformations were to gain commercial profits and were deeply rooted in political, cultural, and social aspects in a "postindustrial, multinational capitalism, consumer, media society".[8]

\section{REASONS FOR THE SUCCESS OF CLOWN FILMS}

In today's the United States, the clown is given a more 
diverse interpretation. Clowns are no longer limited to comedians. Modern films begin to explore the nature of the clown's rebellion and freedom in the context of postmodernism. The success of IT, The Dark Knight, and Joker (2019) can be analyzed from the times, audience, and consumption perspectives.

\subsection{Age}

First, the character of the clown is in line with the times. In an era of postmodernism, suspicion, rebellion, irony, carnival, subversion, and other characteristics can be seen in contemporary America [8]. Since the 1960s, American society has turned into a post-modern historical stage full of contradictions. With the rapid development of advanced knowledge and technology, the American people's spiritual wealth and material wealth are unprecedentedly prosperous. People pursue a more relaxed and comfortable way of leisure. At the same time, they tend to see characters with rich layers. The comedic image of the clown has left a deep impression on people. However, the role is deeply whipped and impacted by the cruelty of real society. People can see themselves in the dark side of the clown, which leads to resonance. The diversity of clown image is an important factor in its success. On the other hand, the legalization, specialization, and systematization of social politics, economy, and culture, as well as the ideology of science and technology, began to control the public's thoughts and spirit. These changes bring fear and fear to human survival. Rich and comfortable life also brings many negative effects. People's emotions gradually tend to narrow. In this era, their desire is constantly amplified. They intend to resist order and power, and they are eager to show their individuality in real society [9]. Clowns are endowed with more characteristics in the form of consciousness. People release their unfulfilled desires and pursuits from the clowns, thus relieving their fear of social oppression. For postmodernism, the best medium is film. Conscious Americans use this channel to visualize and commercialize people's repressed emotions.

\subsection{Audience}

From the audience's perspective, the clown is the outlet of the audience's desire, and the keen producers smell that this kind of film can bring great commercial value [9]. First, the audience is curious about the unknown areas, such as the criminal characteristics of the clown. The image of crime and killers is far away from most people. Clowns are good at camouflage, full of dissatisfaction and resistance to real life under the mask of humor. The audience's curiosity drives them to understand how a terrible killer has experienced a miserable life and how to create a near perfect crime. The valley of terror effect shows that things more like human beings will bring extreme fear to human beings when they exceed the critical point [10]. Clowns exist in real life, but the huge contrast between dramatic and film effects will also magnify people's fear. In addition, the whole film is full of tragic colors, and the purpose of tragedy is to attract pity and sympathy. Clowns are not born like this. He was also full of hope for society and life and had desperate people to love and protect. However, a series of encounters make the original simple clown suffer a profound blow. The audience will sympathize with such characters. Therefore, the film is easy to cause fierce discussion in the society so that the audience can express their resistance to social injustice. The clown is the projection of strong desire, which is consistent with the suppressed needs of the audience.

\subsection{Consumption}

In postmodernism, the procedural and standardized mode of production leads to a sense of loss, making people become economic animals driven by consumption desire. Consumers are eager to get satisfaction in sense and leisure. In recent years, public tastes have developed from single to diversified, and they seek to analyze the realistic factors of social development in the connotation of diversification. Clown movies show complex characters' backgrounds, the dark side of human nature, and other elements, which meet the audience's expectations. In addition, American postmodernism conflicts with traditional aesthetics. The edge of popular culture is broader. Once upon a time, villains would not be the protagonists in works. However, now the audience can accept the villain's things into consumption. Aesthetic is not necessarily only through visual enjoyment. The audience will have a new understanding of "what is beautiful". What is real is beautiful. The clown swings between reality and virtuality, which is also within the scope of aesthetics.

\section{CONCLUSION}

In conclusion, based on combing the birth of clowns and the evolution of their images, this paper analyzes the reasons for the transformation of clowns in American movies after artistic processing in recent years under post-modernism from inside to outside. The clown is no longer just a fool in the traditional sense. His image is constantly being subverted. Especially under the influence of the post-modernism wave, his image has been endowed with more and more profound meanings by people. To some extent, the image of the clown is a redefinition of real life. Similar clown images are no longer limited to American movies, and the development trend of clown images may follow the trend of globalization. 


\section{REFERENCES}

[1] Zhouhan Yang. A Review of Shakespeare: [M]. Beijing: China Social Sciences Press, 1979:89.

[2] Douwe Fokkema. Towards Postmodernism [M]. Ning Wang translated. Beijing: Peking University Press, 1991.

[3] Michel Foucault. Madness and Civilization: [M]. translated by BeiCheng Liu, YuanYing Yang, Beijing: Sanlian Publishing House, 2012:15.

[4] Hassan, Ihab Postmodern Turn: [M] The Ohio State University Press, 1987.

[5] Jean-Francois, Lyptard. The Postmodern Condition: $[\mathrm{M}]$. translated by Geoff Bennington and Brian Massumi. Manchester University Press, 1982
[6] Bazin, André. "THE EVOLUTION OF THE LANGUAGE OF CINEMA". What Is Cinema? Volume I, Berkeley: University of California Press, 2004.

[7] Köhler, W. Gestalt psychology. Psychol. Forsch. 31, XVIII-XXX, 1967.

[8] Fredric Jameson. The Cultural Turn: [M].Verso 1998 Printed by R.R. Donnelley \& Sons, Co. 1983-1998.

[9] Linda Hutcheon. The Politics of Postmodernism: [M]. 2nd edition 2002 Printed by Routledge. 19892002.

[10] Mori, M. Translated by MacDorman, K. F.; Kageki, Norri. The uncanny valley. IEEE Robotics and Automation. doi:10.1109/MRA.2012.2192811. 